\title{
Assessment of Dietary and Life-Style Behaviors of Diabetic and Non-Diabetic Jordanian Atorvastatin Users
}

\author{
Nahla Subhi Al-Bayyari* \\ Department of Nutrition and Food Technology, Faculty of Al-Huson University College,
}

Al-Balqa Applied University, Al-Salt, Jordan.

\begin{abstract}
Received: August 27, 2017; Accepted: September 05, 2017; Published: September 20, 2017
*Corresponding author: Dr. Nahla Subhi Al-Bayyari, Department of Nutrition and Food Technology, Faculty of Al-Huson University College, AlBalqa Applied University, Al-Salt 19117, Jordan, Tel: +962795767524;Fax: +96227012052;E-mail: n.bayyari@bau.edu.jo
\end{abstract}

\begin{abstract}
Objective: To assess and compare the dietary and life-style behaviors among the diabetic and non-diabetic atorvastatin users.

Materials and Methods: A cross-sectional study was conducted on 359 Jordanian patients aged more than 18 years old, using atorvastatin $20 \mathrm{mg} /$ day for at least 6 months and attending the diabetic and endocrine clinics at King Abdullah University Hospital. Dietary and life-style behaviors were assessed and compared among diabetic and non-diabetic patients.Descriptive statistics, Chi-square, student t-test and correlations were performed along with binary logistic regression analysis to examine collectively the association between diabetes and the significant risk factors identified from the univariate analysis.
\end{abstract}

Results: Non-diabetic patients were significantly $(\mathrm{P}<0.05)$ younger, follow low calorie weight reducing diet, loss more weight after diet, eating snacks consist of (artificial juice, ice creams, sweets, chocolates and biscuits, taking supplements and drink amount of alcohol more than the diabetic patients. Female patients $(\mathrm{p}<0.001$; $\mathrm{OR}=3.15)$ eating (sweets, chocolates and biscuits) $(\mathrm{p}<0.05 ; \mathrm{OR}=0.53)$ and having chronic diseases $(\mathrm{p}<0.001 ; \mathrm{OR}=10.27$ ) were more likely to develop diabetes.

Conclusions and Implications: Dietary and life-style behaviors did not differ significantly among diabetic and non-diabetic atorvastatin users. Diet and physical activity life-styles remain essentially unchanged for many patients after using atorvastatin. Involving patients in preventive programs promotes the successful adoption of healthy lifestyles.

Keywords: Diabetes; Atorvastatin; Diet; Life-Style; Behavior

\section{Introduction}

Atorvastatin is a member of lipid lowering drugs called statins. It is prescribed for most of type 2 diabetic patients and non-diabetic patients with hyperlipidemia. In general, patients have hyperlipidemia or hypercholosteremia either diabetic or non-diabetic should modify their dietary and life-style behaviors to improve their lipid profile. However, little is known, of the impact of life-style advices or of patients' behavior around the time of starting statin therapy in primary care.

All over the world, diabetes is one of the rapidly increasing metabolic disorder and an important public health issue. Recently, the International Diabetes Federation (IDF) in 2013, estimated that the number of diabetic adults in the world will increase from 382 million in 2013 to 592 million in less than 25 years[1]. Jordan, like the rest of the world, is experiencing a remarkable increase over the past 10 years in the prevalence of diabetes, and has been reported to be $14.9 \%$ and $12.5 \%$ in men and women, respectively [2].

Several studies have reported that type 2 diabetes can efficiently prevented through a healthy life-style $[3,4]$ such as maintaining a normal body weight [3], being physically active [5], cessation from smoking [6], and eating a healthy diet [7]. Moreover, the moderation in alcohol consumption has been associated with lowering the risk of type 2 diabetes compared with non-alcoholic or with excessive consumption $[8,9]$. Thus, moderate alcohol consumption could be considered as a favorable behavioral lifestyle factor that decreases the risk of type 2 diabetes [10].

The professional diabetes management is based on the balance between healthy eating, physical exercise and medication [11]. However, the problem is most of diabetic patients have little knowledge in determining the recommended quality and quantity of food they should eat to control their blood glucose level. Patient choices in food consumption were based on diabetes nutrition education which concentrates on food intake with low fat, low sodium and high dietary fibers [12].

Evidence suggests that changing of the lifestyle can enhance the effect of statins in lowering cholesterol levels [13]. Although, the lifestyle behaviors of statin users do not differ from nonusers [14]. Therefore, emphasis on the importance of healthy lifestyles and on the role of health professionals in providing their patients with health education, promotion of healthy lifestyle and supporting for changing their behavior is an increasing need [15]. 
Despite of these evidences, previous studies concentrate on healthy life-style behaviors among diabetic patients regardless of the medications prescribed. Therefore, this study objective was to assess and compare the dietary and life-style behaviors among the diabetic and non-diabetic atorvastatin users.

\section{Methods}

\section{Study Design and Humman Participants}

The study design was a cross-sectional conducted at King Abdullah University Hospital (KAUH). The participants were Jordanian patients attending the Diabetes and Endocrine Clinics. The study participants were selected by simple random sampling method from March 2016 to July 2016 and from each individual participant in the study an informed consent was obtained.

\section{Sampling}

The current population sample size allocated according to the prevalence of Jordanian patients using atorvastatin and attending the diabetes and endocrine clinics at KAUH. Therefore, a convenient sample of at least 359 patients was used in this research project.

\section{Inclusion and Exclusion Criteria}

The inclusion criteria were as follows: (1) patients aged more than 18 years (2) attending the diabetic and endocrine clinics at KAUH (3) diagnosed with hyperlipidemia (4) using atorvastatin $20 \mathrm{mg}$ per day for at least six months.

The exclusion criteria included: (1) patients aged less than 18 years (2) attending other clinics at KAUH (3) have normal lipid profile (4) using other statins (4) and using atorvastatin for less than 6 months.

\section{Study Protocol}

A sample of 359 patients visiting the diabetes and endocrine outpatient clinics at KAUH were selected and assessed for eligibility according to the inclusion criteria after the hospital administration and the Institutional Research Board (IRB) committee approval. Patients names, telephone and medical record numbers whose using atorvastatin were adapted from the hospital database. Patients' diagnosis, medical history, the initial body weight, and the concurrent body weight measurements were collected from the patient's medical record. In addition, the dietary and life-style behavior were collected for each selected patient using a structured, reliable and valid questionnaire completed by the research assistant who was trained by the principal researcher. The selected patients using atorvastatin were divided into 2 groups; diabetic and non-diabetic. The dietary and life-style differences between the two groups were analyzed accordingly.

\section{Statistical Analysis}

Collected data were entered in a data sheet and analyzed using SPSS statistical package (IBM, SPSS version 22, 2013) and initially examined by performing descriptive statistics for all categorical and continuous variables. Student t-test, Chi-square and correlation were also applied using the partial correlation function controlling for age and other confounding variables. A multivariable binary logistic regression analysis was performed to examine collectively the association between diabetes and the significant risk factors identified from the univariate analysis. Level of $\mathrm{P} \leq 0.05$ was considered as significant.

\section{Results}

\section{Socio-Demographic and Medical Characteristics}

The Mean age of the study participants was $62.88 \pm 0.6$ year. The distribution of the study sample according to gender showed that $53.3 \%$ vs. $46.5 \%$ were male and female respectively, $90 \%$ were married, $29.2 \%$ of the samples were highly educated and $51.8 \%$ their monthly income was between $201-500$ JD. On the other hand, $87.5 \%$ of the study sample were having chronic diseases (cardiovascular, hypertension, diabetes, thyroid malfunctioning) and $68.8 \%$ of them having diabetes, $65.2 \%$ having a family history of hypocholesteremia, and $72.7 \%$ using atorvastatin for more than 2 years.

\section{Dietary and Life-Style Characteristics}

The arithmetic means and standard errors of the means for dietary and life-style behavior were shown in (Table 1). It was noticed that the mean body weight after using atorvastatin $(84.51 \pm 2.47)$ was higher than the mean body weight before using atorvastatin $(80.30 \pm 0.70)$ among the total study sample. This could be related to atorvastatin or dietary and life-style behavior.

The frequencies of the study participants categorical variables according to dietary and life- style behavior among the 359 patients were also shown in (Table 1); around 33\% of the study sample were playing sports on regular basis, $23.4 \%$ were smokers, $1.1 \%$ were alcoholic, $90.8 \%$ were coffee drinkers, $11.7 \%$ were follow a weight reducing diet, $71.9 \%$ were always eating breakfast, $84.4 \%$ were eating snacks, $32.9 \%$ were fast food eaters, $22.6 \%$ eating more than one type of fast food, $50.4 \%$ were eating food rich in cholesterol, $98.6 \%$ were using margarine and/ or vegetable oils in preparing their food, $93.8 \%$ of them were using olive oil in their diet and $44.3 \%$ were taking supplements.

\section{Descriptive Statistics and Mean Comparisons between Diabetic and Non-Diabetic Patients}

The descriptive statistics and mean comparisons of age, weight, dietary and life-style behavior after stratifying of the study sample into two groups the diabetic and non-diabetic patients using independent sample T-test were shown in (Table 2). Results showed that there was a statically significant difference ( $\mathrm{P} \leq$ $0.05)$ between both groups regarding age $(\mathrm{P}=0.04)$, weight loss after diet $(\mathrm{P}=0.002)$ and the mean difference in alcohol drinking quantity $(\mathrm{P}=0.001)$.

\section{Comparing frequencies (cross tabulation) between diabetic and non-diabetic patients}

The frequencies of the personal information between diabetic and non-diabetic patients in the study sample showed that there was only a statistically significant difference $(\mathrm{P} \leq 0.05)$ between 
the study groups gender, where the frequency of diabetic females is significantly $(\mathrm{P}=0.001)$ higher than males. Also, frequencies of medical history showed that there was only a statistically significant difference $(\mathrm{P} \leq 0.05)$ regarding history of chronic diseases $(\mathrm{P}=0.001)$ were $94.7 \%$ of the diabetic patients having chronic diseases compared with $70.5 \%$ of non-diabetic patients.

Comparing the frequencies of dietary and life-style behavioral variables among the diabetic and non-diabetic patients, results showed that non-diabetic patients were statistically and significantly $(\mathrm{p}<0.05)$ have higher frequency of smoking $(\mathrm{p}=0.003)$, following low calorie weight reducing diet $(\mathrm{p}=0.01)$, eating snacks consist of artificial juice and ice creams $(p=0.04)$, eating snacks consist of sweets, chocolates and biscuits $(\mathrm{p}=0.003)$ as well as taking supplements $(\mathrm{p}=0.05)$ more than the diabetic patients (Table 2).

Table 1: Descriptive Statistics of Age, Weight, Dietary and Life-Style Behavior for all study participants $(\mathrm{N}=359)$

\begin{tabular}{|c|c|c|c|}
\hline Variable & Mean \pm S.E.M & Minimum & Maximum \\
\hline Age (year) & $62.88 \pm 0.60$ & 31.0 & 89.0 \\
\hline $\begin{array}{l}\text { Weight before using } \\
\text { atorvastatin }(\mathrm{kg})\end{array}$ & $80.30 \pm 0.70$ & 7.0 & 129.0 \\
\hline $\begin{array}{l}\text { Weight after using } \\
\text { atorvastatin }(\mathrm{kg})\end{array}$ & $84.51 \pm 2.47$ & 47.0 & 122.0 \\
\hline Sport time (min/day) & $43.54 \pm 2.65$ & 0.0 & 180.0 \\
\hline $\begin{array}{l}\text { Number of cigarettes } \\
\text { smoked/day }\end{array}$ & $23.49 \pm 1.50$ & 0.0 & 60.0 \\
\hline $\begin{array}{l}\text { Alcohol quantity (cup/ } \\
\text { day) }\end{array}$ & $2.25 \pm 0.25$ & 2.0 & 3.0 \\
\hline Soft drinks (cup/day) & $1.33 \pm 0.06$ & 0.25 & 6.0 \\
\hline $\begin{array}{l}\text { Coffee quantity (cup/ } \\
\text { day) }\end{array}$ & $2.62 \pm 0.10$ & 0.5 & 14.0 \\
\hline $\begin{array}{l}\text { Milk quantity (cup/ } \\
\text { day) }\end{array}$ & $1.45 \pm 0.04$ & 0.0 & 8.0 \\
\hline \multirow[t]{2}{*}{$\begin{array}{l}\text { Weight loss due to diet } \\
(\mathrm{kg})\end{array}$} & $3.64 \pm 0.67$ & 0.0 & 20.0 \\
\hline & & $\begin{array}{l}\text { Frequency } \\
\text { (n) }\end{array}$ & $\%$ \\
\hline \multicolumn{2}{|c|}{ Play sports on a Regular Basis } & 118 & 32.9 \\
\hline \multicolumn{2}{|l|}{ Daily light sport } & 112 & 95.0 \\
\hline \multicolumn{2}{|c|}{ Sport type (walking or running) } & 112 & 95.0 \\
\hline \multicolumn{2}{|l|}{ Smoking } & 84 & 23.4 \\
\hline \multicolumn{2}{|l|}{ Drinking alcohol } & 4 & 1.1 \\
\hline \multicolumn{2}{|l|}{ Drinking soft drinks } & 166 & 46.2 \\
\hline \multicolumn{2}{|l|}{ Drinking soft drinks daily } & 31 & 18.7 \\
\hline \multicolumn{2}{|l|}{ Drinking coffee } & 326 & 90.8 \\
\hline \multicolumn{2}{|l|}{ Drinking coffee daily } & 260 & 79.8 \\
\hline \multicolumn{2}{|c|}{ Follow weight reducing diet } & 42 & 11.7 \\
\hline \multicolumn{2}{|c|}{ Low calorie weight reducing diet } & 32 & 76.2 \\
\hline \multicolumn{2}{|c|}{ Eating meals on a regular basis } & 249 & 69.4 \\
\hline
\end{tabular}

\begin{tabular}{|l|c|c|}
\hline Eating three meals per day & 132 & 36.8 \\
\hline Always eating breakfast & 258 & 71.9 \\
\hline Eating snacks & 303 & 84.4 \\
\hline Eating two snacks per day & 111 & 36.6 \\
\hline Drinking milk & 322 & 89.7 \\
\hline Drinking milk daily & 219 & 68.0 \\
\hline Eating sea food & 278 & 77.4 \\
\hline Eat fish or sea food monthly & 176 & 49.0 \\
\hline Eating fast food & 118 & 32.9 \\
\hline Eating fast food daily & 14 & 11.9 \\
\hline Eating hamburger, fried chicken and & 81 & 68.6 \\
\hline pizza & 181 & 50.4 \\
\hline Eating foods rich in cholesterol & 238 & 66.3 \\
\hline Eating vegetables and whole grains & 18 & 5.0 \\
\hline Food allergy & 354 & 98.6 \\
\hline $\begin{array}{l}\text { Using margarine and/or vegetable oils } \\
\text { in food preparation }\end{array}$ & 332 & 93.8 \\
\hline Using olive oil & 264 & 74.6 \\
\hline Using corn oil & 12 & 3.4 \\
\hline Using palm oil & 45 & 12.7 \\
\hline Using other fats and oils & 759 & 44.3 \\
\hline Taking supplements & 54 & 39.0 \\
\hline Taking omega-3 & 47.2 \\
\hline Taking multivitamins & 38.4 \\
\hline Taking vitamin D & 34.0 \\
\hline Taking other supplements & 159 \\
\hline Vales are presented as means and stan & & \\
\hline
\end{tabular}

Values are presented as means and standard error of the means (mean \pm S.E.M), frequencies (n) and percentages (\%).

Table 2: Frequencies and Mean Comparisons of Age, Weight, Dietary and Life-Style Behavior for Diabetic and Non-Diabetic Patients. $(\mathrm{N}=359)$.

\begin{tabular}{|l|c|c|c|}
\hline \multicolumn{1}{|c|}{ Variable } & DM (n=247) & $\begin{array}{c}\text { NDM } \\
\text { (n=112) }\end{array}$ & \multirow{2}{*}{ P-Value } \\
\cline { 2 - 4 } & Mean \pm S.E.M & $\begin{array}{c}\text { Mean } \pm \\
\text { S.E.M }\end{array}$ & \\
\hline Age (year) & $63.67 \pm 0.68$ & $61.13 \pm 1.16$ & $.04^{*}$ \\
\hline $\begin{array}{l}\text { Weight before using } \\
\text { atorvastatin (kg) }\end{array}$ & $80.55 \pm 0.79$ & $79.75 \pm 1.42$ & .60 \\
\hline $\begin{array}{l}\text { Weight after using } \\
\text { atorvastatin (kg) }\end{array}$ & $85.76 \pm 3.54$ & $81.75 \pm 1.25$ & .45 \\
\hline Sport time (min/day) & $43.99 \pm 3.43$ & $42.56 \pm 3.94$ & .80 \\
\hline $\begin{array}{l}\text { Number of cigarettes } \\
\text { smoked/day }\end{array}$ & $23.20 \pm 2.11$ & $23.85 \pm 2.15$ & .83 \\
\hline $\begin{array}{l}\text { Alcohol quantity (cup/ } \\
\text { day) }\end{array}$ & $2.00 \pm 0.00$ & $3.00 \pm 0.00$ & $<.001 *$ \\
\hline Soft drinks (cup/day) & $1.32 \pm 0.07$ & $1.35 \pm 0.10$ & .81 \\
\hline Coffee quantity (cup/day) & $2.51 \pm 0.13$ & $2.86 \pm 0.18$ & .12 \\
\hline Milk quantity (cup/day) & $1.43 \pm 0.04$ & $1.51 \pm 0.10$ & .40 \\
\hline
\end{tabular}




\begin{tabular}{|c|c|c|c|}
\hline $\begin{array}{l}\text { Weight loss due to diet } \\
(\mathrm{kg})\end{array}$ & $2.52 \pm 0.29$ & $7.00 \pm 2.25$ & $.002^{*}$ \\
\hline & n (\%) & n (\%) & $\left(\chi^{2}\right)$ \\
\hline $\begin{array}{l}\text { Play sports on a Regular } \\
\text { Basis }\end{array}$ & $80(32.4)$ & $38(34.0)$ & .43 \\
\hline Smoking & $47(19.0)$ & $37(33.0)$ & $.003^{*}$ \\
\hline Drinking alcohol & $3(1.2)$ & $1(0.9)$ & .63 \\
\hline Drinking soft drinks & $107(43.3)$ & $59(52.7)$ & .07 \\
\hline Drinking coffee & 227 (91.9) & $99(88.4)$ & .20 \\
\hline $\begin{array}{l}\text { Follow weight reducing } \\
\text { diet }\end{array}$ & $28(11.3)$ & 13 (11.6) & .54 \\
\hline $\begin{array}{l}\text { Low calorie weight } \\
\text { reducing diet }\end{array}$ & $19(7.7)$ & 13 (11.6) & $.01^{*}$ \\
\hline $\begin{array}{l}\text { Eating meals on a regular } \\
\text { basis }\end{array}$ & 177 (71.7) & $72(64.3)$ & .10 \\
\hline Always eating breakfast & 177 (71.7) & $81(72.3)$ & .50 \\
\hline Eating snacks & $210(85.0)$ & $93(83.0)$ & .37 \\
\hline $\begin{array}{l}\text { Eating snacks (fruits and } \\
\text { fresh juice) }\end{array}$ & $221(89.5)$ & $99(88.4)$ & .40 \\
\hline $\begin{array}{l}\text { Eating snacks (artificial } \\
\text { juice and ice creams) }\end{array}$ & $17(6.9)$ & $15(13.4)$ & $.04^{*}$ \\
\hline $\begin{array}{l}\text { Eating snacks (sweets, } \\
\text { chocolates and biscuits) }\end{array}$ & 47 (19.0) & $37(33.0)$ & $.003^{*}$ \\
\hline $\begin{array}{l}\text { Eating snacks (salty } \\
\text { crackers) }\end{array}$ & $26(10.5)$ & $14(12.5)$ & .36 \\
\hline Drinking milk & $220(89.1)$ & 102 (91.1) & .35 \\
\hline Eating sea food & $189(76.5)$ & $90(80.4)$ & .25 \\
\hline Eating fast food & $76(30.8)$ & $42(37.5)$ & .13 \\
\hline $\begin{array}{l}\text { Eating hamburger, fried } \\
\text { chicken and pizza }\end{array}$ & $20(8.1)$ & $39(34.8)$ & .50 \\
\hline $\begin{array}{l}\text { Eating foods rich in } \\
\text { cholesterol }\end{array}$ & $123(49.8)$ & $59(52.7)$ & .35 \\
\hline $\begin{array}{l}\text { Eating vegetables and } \\
\text { whole grains }\end{array}$ & $159(64.4)$ & $79(70.5)$ & .15 \\
\hline Food allergy & $15(6.1)$ & $3(2.7)$ & .13 \\
\hline $\begin{array}{l}\text { Using margarine and/ } \\
\text { or vegetable oils in food } \\
\text { preparation }\end{array}$ & $243(98.4)$ & 111 (99.1) & .50 \\
\hline Using olive oil & 227 (91.9) & $105(93.8)$ & .35 \\
\hline Using corn oil & $176(71.3)$ & 88 (78.6) & .10 \\
\hline Using palm oil & $9(3.6)$ & $3(2.7)$ & .45 \\
\hline Using other fats and oils & 32 (12.9) & $13(11.6)$ & .43 \\
\hline Taking supplements & $102(41.3)$ & $57(50.9)$ & $.05^{*}$ \\
\hline Taking omega-3 & $41(16.6)$ & $21(18.8)$ & .36 \\
\hline Taking multivitamins & 49 (19.8) & $26(23.2)$ & .28 \\
\hline Taking vitamin D & 49 (19.8) & $29(25.9)$ & .13 \\
\hline Taking other supplements & $35(14.2)$ & $19(17.0)$ & .30 \\
\hline
\end{tabular}

\section{Binary Logistic Regression Model of Diabetes}

The final model of the binary logistic regression of diabetes includes three significant $(\mathrm{p} \leq 0.05)$ contributing and predicting factors. The likelihood of eating (sweets, chocolates and biscuits) as snacks was about half times $(\mathrm{p}<0.05 ; 0 R=0.53)$ more likely to develop diabetes than the non-eaters. Females were about 3 times $(\mathrm{p}<0.001 ; \mathrm{OR}=3.15)$ more likely to develop diabetes than males. In addition, the likelihood of patients having chronic diseases (CVD, hypertension and thyroid problems) was 10 times $(\mathrm{p}<0.001 ; \mathrm{OR}=10.27)$ more likely to develop diabetes (Table 3$)$.

\section{Discussion}

The study findings showed that the mean body weight of the atorvastatin users was increased after using atorvastatin; most of the study participants were drinking coffee and using olive oil in preparing their food. More than the half eating vegetables and whole grains and always eating their breakfast. Also, around the third of them eating three meals per day and few of them eating fast food daily. Comparing the diabetic and nondiabetic atorvastatin users there was a significant difference in the means of age, alcohol consumption and the weight loss due to diet. Diabetic patients were older, drink less alcohol and lost few kilograms from their body weight due to diet compared with the non-diabetic. In addition, diabetic patients were significantly had low frequencies of smokers, followers of low calorie weight reducing diet, and low eaters of snacks consist of artificial juice, ice cream, sweets, chocolates and biscuits compared with nondiabetic patients. The logistic regression model showed that the presence of chronic diseases (hypertension, cardio-vascular and thyroid problems), being a female and eating snacks consist of sweets, chocolates and biscuits increased the likelihood of developing diabetes.

Recently, similar results were reported in a United Kingdome population study, which found that the initiation of statin prescription was not associated with adoption of healthy diet or physical activity behaviors for most patients. However, approximately one third of the sample improved their diet with the first time of statin prescription, whilst, at 1 month and 4 months later approximately $40 \%$ continued to consume higher levels of fat than advised, $55 \%$ consumed low levels of fiber and over $80 \%$ were insufficiently active for health benefits [16]. It has been reported that moderate alcohol consumption does not have major detrimental effects on long-term blood glucose control in people with diabetes. Risks associated with alcohol consumption include hypoglycemia (particularly for those using insulin therapies), weight gain, and hyperglycemia (for those consuming excessive amounts) $[17,18]$.This could be explained by the significant low alcohol consumption among the diabetic compared with non-diabetic patients in this study.

Vitamins or minerals supplementation for diabetic patients without reporting deficiencies has no clear evidence. ${ }^{17}$ Metformin is associated with vitamin B12 deficiency as reported recently, thus, it was suggested that vitamin B12 levels should be tested periodically for metformin treated patients [19]. Routine supplementation with vitamins $\mathrm{E}$ and $\mathrm{D}$ or other micronutrients 


\begin{tabular}{|c|c|c|c|c|c|c|}
\hline \multirow[t]{2}{*}{ Variable } & \multirow[t]{2}{*}{$\mathbf{b}$} & \multirow[t]{2}{*}{ S.E. } & \multirow[t]{2}{*}{ P-Value } & \multirow[t]{2}{*}{ OR } & \multicolumn{2}{|c|}{ 95\% C.I for OR } \\
\hline & & & & & Lower & Upper \\
\hline $\begin{array}{l}\text { Eating snacks (sweets, } \\
\text { chocolates and biscuits) }\end{array}$ & -0.63 & 0.32 & $.04^{*}$ & 0.53 & 0.29 & 0.99 \\
\hline Age & 0.01 & 0.01 & .44 & 1.01 & 0.98 & 1.04 \\
\hline Gender (female) & 1.14 & 0.28 & $<.001^{*}$ & 3.15 & 1.83 & 5.41 \\
\hline Hypertension & -0.24 & 0.29 & .39 & 0.78 & 0.44 & 1.38 \\
\hline Presence of chronic diseases & 2.33 & 0.42 & $<.001^{*}$ & 10.27 & 4.55 & 23.18 \\
\hline Body weight & 0.01 & 0.01 & .11 & 1.02 & 0.99 & 1.04 \\
\hline Play sports on regular basis & 0.26 & 0.30 & .37 & 1.30 & 0.73 & 2.33 \\
\hline Drinking soft drinks & -0.12 & 0.30 & .68 & 0.89 & 0.50 & 1.58 \\
\hline Follow weight reducing diet & 0.20 & 0.43 & .64 & 1.22 & 0.53 & 2.83 \\
\hline Drinking coffee & 0.67 & 0.43 & .11 & 1.95 & 0.85 & 4.50 \\
\hline Eating breakfast & -0.01 & 0.19 & .95 & 0.99 & 0.68 & 1.44 \\
\hline Eating fast food & -0.02 & 0.33 & .95 & 0.98 & 0.52 & 1.88 \\
\hline Constant & -3.96 & 1.38 & .004 & 0.02 & & \\
\hline $\begin{array}{l}\text { 1- Hosmer and Lemeshow tes } \\
\text { 2- b: Regression coefficient. } \\
\text { 3- S.E.: Standard error of the } \\
\text { 4- CI: Confidence Interval. } \\
\text { 5- *p-value } \leq 0.05 \text { is statistical }\end{array}$ & $\begin{array}{l}\text { ession co } \\
\text { gnifican }\end{array}$ & $p$-valu & & & & \\
\hline
\end{tabular}

[20] is not advised, because of insufficient evidence to improve glycemic control in diabetic patients $[17,18]$. Similarly, in this study diabetic patients were less frequent in taking supplements compared with non-diabetic which could be attribuated to previous findings and medical advices through routine follow up and diabetic care.

Recent data show tobacco use is higher among adults with chronic conditions [21]. Other studies of individuals with diabetes consistently demonstrate that smokers and passive smokers have a higher risk of CVD, premature death, and micro vascular complications, and smoking may have a role in the development of type 2 diabetes [22]. A study on smokers newly diagnosed with type 2 diabetes found that smoking cessation was associated with amelioration of metabolic parameters and reduced blood pressure and albuminuria at 1 year [23].These results were consistence with this epidemiological study. Physical activity including all exercises is an important part of the diabetes management plan. Exercise has been shown to improve blood glucose control, reduce cardiovascular risk factors, contribute to weight loss, and improve well-being. It has been recommended that all adults, and particularly those with type 2 diabetes, should decrease the time spent in daily sedentary behavior and prolonged sitting should be interrupted every $30 \mathrm{~min}$ for blood glucose benefits [24].Unfortunately, around two third of this study participants were physically inactive and the time spend during exercise for physically active ones was relatively low compared with the recommended time.

Body weight management is an important part of diabetes care plan for overweight and obese people with diabetes.
Therefore, life-style intervention programs should be intensive and have frequent follow-up to achieve significant weight reductions and improve clinical parameters such as lipid profile [24].Many studies found strong and consistent evidence that modest persistent weight loss can delay the progression from pre diabetes to type 2 diabetes $[25,26]$ and is beneficial to the management of type 2 diabetes. Modest weight loss (reduction of $5 \%$ of initial body weight), has been shown to improve glycemic control and to reduce the need for glucose-lowering medications $[27,28]$. For many obese individuals, with type 2 diabetes, weight Loss $>5 \%$ is needed to produce beneficial outcomes in glycemic control, lipids, and blood pressure. Whilst sustained weight loss of $>7 \%$ is the optimal [29].The diets used in intensive lifestyle management for weight loss should emphasis on nutrient dense foods, such as whole grains, vegetables, fruits, legumes, low-fat dairy, lean meats, nuts, and seeds, as well as on achieving the desired energy deficit $[30,32]$. In this study, small portion of the diabetic patients were using the low-calorie weight reducing diet and the amount of weight loss due to diet was relatively low compared with non-diabetic which disagree with body weight management recommendations. Although, diabetic patients were less eaters of snacks consist of artificial juice, ice cream, sweets, chocolates and biscuits and more than the half of them eat vegetables and whole grains seeds but around $50 \%$ of them eat foods rich in cholesterol. These results along with the low rate of physical activity could explain the small reduction in body weight among the diabetic group compared with previous studies.

A meta-analysis in Sub-Saharan Africa demonstrated that, men in Eastern, Middle and Southern Africa had a significantly 
higher prevalence of impaired fasting glycaemia and a lower prevalence of impaired glucose tolerance compared with the women. Although, the overall prevalence of diabetes mellitus did not significantly differ by sex but the prevalence of diabetes mellitus was found to be lower or higher in women than in men when examined by African sub-region [33]. Although, diabetes is more prevalent in males than in females [34], in this study, women were more likely to have diabetes. Controversial results could be attributed to the diversity in body composition such as low muscle mass compared to fat mass, endocrine imbalances, psychological stress and genetics [34].

Compared with individuals without diabetes, patients with type 2 diabetes mellitus have higher risk of cardiovascular morbidity and mortality. Most of this higher risk is associated with enhanced prevalence of well-known risk factors such as hypertension, dyslipidemia and obesity in these patients [35]. Hypertension is present in more than $60 \%$ of type 2 diabetes patients [36].Hypertension and diabetes mellitus are multilateral risk factors for cardiovascular diseases. Diabetes doubles the cardiovascular risk in men and more than triples the risk in women, hypertension quadruple cardiovascular risk in diabetic patients [37]. Similarly, in this study the risk of diabetes increases with the presence of chronic diseases as well as diabetes increases the risk of other chronic diseases such as hypertension and cardiovascular diseases.

Finally, the study had limitations including the cross-sectional design, the small sample size and lacking dietary, biochemical and clinical assessments. Therefore, prospective longitudinal follow up study with large cohort including healthy population assessed biochemically, clinically and dietary using 24-hour recall or food frequency questionnaire to determine the total calories, macro and micronutrients consumed would help confirm these results.

\section{Conclusions and Implications}

Our findings showed that most of dietary and life-style behaviors did not differ significantly among diabetic and nondiabetic atorvastatin users. Nevertheless, diabetic patients showed better dietary behavioral modifications than the nondiabetic except for the weight reducing diet. Diet and physical activity life-styles remain essentially unchanged for many patients after using atorvastatin, with higher consumption of saturated fat, less dietary fiber and lower levels of physical activity than recommended. Also, the risk of diabetes increases among females, eating snacks consist of sweets, chocolates and biscuits and having chronic diseases. Involving patients in preventive programs promotes the successful adoption of healthy lifestyles. Physicians should pay their utmost attention to non-diabetic as well as diabetic patients who are treated with atorvastatin to make a qualitative change in their eating and daily life-style behaviors to control blood glucose levels and prevent medical complications for diabetics and to reduce risk of developing diabetes in future for the non-diabetics.

\section{Acknowledgements}

The author thanks the study participants who participated in this study and the King Abdullah University Hospital (KAUH) which helped with recruitment.

\section{Declarations}

The author declares no conflict of interest. This research was not funded by any organization and it was approved by the KAUH Institutional Research Board (IRB) committee.

\section{References}

1. Guariguata L, Whiting D, Hambleton I, Beagley J, Linnenkamp U, Shaw J. Global estimates of diabetes prevalence for 2013 and projections for 2035. Diabetes Res Clin Pract . 2014;103(2):137-149. Doi: 10.1016/j. diabres.2013.11.002.

2. Ajlouni K, Khader Y, Batieha A, Ajlouni H, El-Khateeb M. An increase in prevalence of diabetes mellitus in Jordan over 10 years. J Diabetes Complications .2008;22(5):317-324. Doi: 10.1016/j. jdiacomp.2007.01.004

3. Hu FB, Manson JE, Stampfer MJ, Colditz G, Liu S, Solomon CG, et al. Diet, lifestyle, and the risk of type 2 diabetes mellitus in women. $\mathrm{N}$ Engl J Med. 2001;345(11):790-797. Doi: 10.1056/NEJMoa010492

4. Mozaffarian D, Kamineni A, Carnethon M,Djousse L, Mukamal KJ, Siscovick D. Lifestyle risk factors and new-onset diabetes mellitus in older adults: the cardiovascular health study. Arch Intern Med. 2009;169(8):798-807. Doi: 10.1001/archinternmed.2009.21

5. Wannamethee SG, Shaper AG, Alberti KG. Physical activity, metabolic factors, and the incidence of coronary heart disease and type 2 diabetes.Arch Intern Med. 2000;160(14):2108-2116.

6. Rimm EB, Manson JE, Stampfer MJ, Colditz GA, Willett WC, Rosner B, et al. Cigarette smoking and the risk of diabetes in women. Am J Public Health. 1993;83(2):211-214.

7. Liese AD, Nichols M, Sun X, D’Agostino RB Jr, Haffner SM. Adherence to the DASH Diet is inversely associated with incidence of type 2 diabetes: the insulin resistance atherosclerosis study. Diabetes Care. 2009;32(8):1434-1436. Doi: 10.2337/dc09-0228

8. Koppes LLJ, Dekker JM, Hendriks HFJ, Bouter LM, Heine RJ. Moderate alcohol consumption lowers the risk of type 2 diabetes: a meta analysis of prospective observational studies. Diabetes Care. 2005;28(3):719725 .

9. Baliunas DO, Taylor BJ, Irving H, Roerecke M, Patra J, Mohapatra S, et al. Alcohol as a risk factor for type 2 diabetes: a systematic review and meta-analysis. Diabetes Care. 2009;32(11):2123-2132. Doi: 10.2337/ dc09-0227

10. Joosten MM, Grobbee DE, L van der AD, Verschuren WMM, Hendriks HFJ, Beulens JWJ. Combined effect of alcohol consumption and lifestyle behaviors on risk of type 2 diabetes. Am J ClinNutr. 2010;91(6):17771783. Doi: $10.3945 / a j c n .2010 .29170$

11.CDC. National diabetes fact sheet: National estimates and general information on diabetes and pre diabetes in the United States, 2011. Atlanta, GA: U.S. Department of Health and Human Services, Centers for Disease Control and Prevention, 2011. Accessed July17, 2017.

12. Shamsi N, Shehab Z, AlNahash Z, AlMuhanadi S, Al-Nasir F. Factors Influencing Dietary Practice among Type 2 Diabetics. Bahrain Med Bull. 2013;35(3):1-14.

13. Kokkinos PF, Faselis C, Myers J, Panagiotakos D, Doumas M. Interactive effects of fitness and statin treatment on mortality risk in veterans with dyslipidaemia: A cohort study. Lancet. 2013;381(9864):394399. Doi: 10.1016/S0140-6736(12)61426-3 
14. Savolainen J, Kautiainen H, Niskanen L, Mäntyselkä P. Decreasing cholesterol levels in the community - lifestyle change with statin? BMC Fam Pract. 2015;16:29. Doi:10.1186/s12875-015-0240-y

15. Perk J, De Backer G, Gohlke H, Graham I, Reiner Z, Verschuren WMM, et al. European Guidelines on cardiovascular disease prevention in clinical practice (version 2012). The Fifth Joint Task Force of the European Society of Cardiology and Other Societies on Cardiovascular Disease Prevention in Clinical Practice. Eur Heart J. 2012;33(13):16351701. Doi:10.1093/eurheartj/ehs092

16. McAleer1 SF, Cupples ME, Neville1 CE, McKinley MC, Woodside JV, Tully MA. Statin prescription initiation and lifestyle behavior: a primary care cohort study. BMC Fam Pract.2016; 17:77. Doi: 10.1186/ s12875-016-0471-6

17. Evert AB, Boucher JL, Cypress M, Dunbar SA, Franz MJ, Mayer-Davis EJ, et al. Nutrition therapy recommendations for the management of adults with diabetes. Diabetes Care. 2013;36(11):3821-3842. Doi: $10.2337 / \mathrm{dc} 13-2042$

18. Mozaffarian D. Dietary and policy priorities for cardiovascular disease, diabetes, and obesity: a comprehensive review. Circulation. 2016;133:187-225. Doi: 10.1161/CIRCULATIONAHA.115.018585

19. Aroda VR, Edelstein SL, Goldberg RB, Knowler WC, Marcovina SM Orchard TJ, et al. Long-term metform in use and vitamin B12 deficiency in the Diabetes Prevention Program Outcomes Study. J Clin Endocrinol Metab. 2016;101(4):1754-1761. Doi: 10.1210/jc.2015-3754

20. Mitri J, Pittas AG. Vitamin D and diabetes. EndocrinolMetabClin North Am. 2014;43(1):205-232. Doi: 10.1016/j.ecl.2013.09.010

21. Stanton CA, Keith DR, Gaalema DE, Bunn JY, Doogan NJ, Redner R, et al. Trends in tobacco use among US adults withchronic health conditions: National Survey on Drug Use and Health 2005-2013. Prev Med. 2016;92:160-168. Doi: 10.1016/j.ypmed.2016.04.008

22. Jankowich M, Choudhary G, Taveira TH, Wu WC. Age-, race-, and gender-specific prevalence of diabetes among smokers. Diabetes Res ClinPract. 2011;93(3):101-105. Doi: 10.1016/j.diabres.2011.05.029

23. Voulgari C, Katsilambros N, Tentolouris N. Smoking cessation predicts amelioration of micro albuminuria in newly diagnosed type 2 diabetes mellitus: a 1-year prospective study. Metabolism. 2011;60(10):14561464. Doi: 10.1016/j.metabol.2011.02.014

24. American Diabetes Association. Lifestyle Management. Diabetes Care. 2017;40(Suppl. 1):S33-D43. Doi: 10.2337/dc17-S007

25. Mudaliar U, Zabetian A, Goodman M, Echouffo-Tcheugui JB, Albright $\mathrm{AL}$, Gregg EW, et al. Cardio metabolic risk factor changes observed in diabetes prevention programs in US settings: a systematic review and meta-analysis. PLoS Med. 2016;13(7):e1002095.Doi: 10.1371/ journal.pmed.1002095

26. Balk EM, Earley A, Raman G, Avendano EA, Pittas AG, Remington PL. Combined diet and physical activity promotion programs to prevent type 2 diabetes among persons at increased risk: a systematic review for the Community Preventive Services Task Force. Ann Intern Med. 2015;163(6):164-175. Doi: 10.7326/M15-0452
27. Goldstein DJ. Beneficial health effects of modest weight loss. Int J Obes Relat Metab Disord. 1992;16(6):397-415

28. Pastors JG, Warshaw H, Daly A, Franz M, Kulkarni K. The evidence for the effectiveness of medical nutrition therapy in diabetes management. Diabetes Care. 2002;25(3):608-613.

29. Franz MJ, Boucher JL, Rutten-Ramos S, Van Wormer JJ. Lifestyle weight-loss intervention outcomes in overweight and obese adults with type 2 diabetes: a systematic review and meta-analysis of randomized clinical trials. J AcadNutr Diet. 2015;115(9):1447-1463. Doi: 10.1016/j.jand.2015.02.031

30. de Souza RJ, Bray GA, Carey VJ, Hall KD, LeBoff MS, Loria CM, et al. Effects of 4 weight-loss diets differing in fat, protein,and carbohydrate on fat mass, lean mass, visceral adipose tissue, and hepatic fat: results from the POUNDS LOST trial. Am J ClinNutr. 2012;95(3):614-625. Doi: 10.3945/ajcn.111.026328

31. Johnston BC, Kanters S, Bandayrel K, Wu P, Naji F, Siemieniuk RA, et al. Comparison of weight loss among named diet programs in overweight and obese adults: a meta-analysis. JAMA. 2014;312(9):923-933. Doi: 10.1001/jama.2014.10397

32. Fox CS, Golden SH, Anderson C, Bray GA, Burke LE, de Boer IH, et al. Update on Prevention of Cardiovascular Disease in Adults With Type 2 Diabetes Mellitus in Light of Recent Evidence: A Scientific Statement From the American Heart Association and the American Diabetes Association. Diabetes Care. 2015;38(9):1777-1803. Doi: 10.2337/ dci15-0012

33. Hilawe EH, Yatsuya H, Kawaguchi L, Aoyama A. Differences by sex in the prevalence of diabetes mellitus, impaired fasting glycaemia and impaired glucose tolerance in sub-Saharan Africa: a systematic review and meta-analysis. Bull World Health Organ. 2013;91(9):671-682D. Doi: 10.2471/BLT.12.113415

34. Kautzky-Willer A, Harreiter J, Pacini G. Sex and Gender Differences in Risk, Pathophysiology and Complications of Type 2 Diabetes Mellitus. Endocr Rev. 2016;37(3):278-316. Doi: 10.1210/er.2015-1137

35. Martín-Timón I, Sevillano-Collantes C, Segura-Galindo A, CañizoGómez FJ. Type 2 diabetes and cardiovascular disease: Have all risk factors the same strength? World J Diabetes. 2014;5(4):444-470. Doi: $10.4239 /$ wjd. v5.i4.444

36. Nilsson PM, Cederholm J, Zethelius BR,Eliasson BR, EegOlofsson K, GudbjRnsdottir S. Trends in blood pressure control in patients with type 2 diabetes: data from the Swedish National Diabetes Register (NDR). Blood Press. 2011;20(6):348-354. doi: $10.3109 / 08037051.2011 .587288$

37. Mogensen CE. New treatment guidelines for a patient with diabetes and hypertension. J Hypertens Suppl. 2003;21:25-30. 